\title{
Erratum to: MRI evaluation of the knee in children with infantile Blount disease: tibial and extra-tibial findings
}

\author{
Victor Ho-Fung • Camilo Jaimes • Jorge Delgado • \\ Richard S. Davidson • Diego Jaramillo
}

Published online: 28 May 2013

(C) Springer-Verlag Berlin Heidelberg 2013

\section{Erratum to: Pediatr Radiol \\ DOI 10.1007/s00247-013-2686-1}

The name of the third author was misspelled in the manuscript submitted for publication.

We are pleased to redress this regrettable error here.

The online version of the original article can be found at http://dx.doi.org/ 10.1007/s00247-013-2686-1.

V. Ho-Fung $(\bowtie) \cdot$ C. Jaimes $\cdot$ J. Delgado $\cdot$ D. Jaramillo Department of Radiology, The Children's Hospital of Philadelphia, 34th Street \& Civic Center Boulevard,

Philadelphia, PA 19104, USA

e-mail: hov@email.chop.edu

V. Ho-Fung $\cdot$ D. Jaramillo

Department of Radiology, The Perelman School of Medicine at the University of Pennsylvania, Philadelphia, PA, USA

R. S. Davidson

Department of Orthopedic Surgery, The Children's Hospital of Philadelphia, 34th Street \& Civic Center Boulevard Philadelphia, PA, USA

R. S. Davidson

Department of Orthopedic Surgery, The Perelman School of Medicine at the University of Pennsylvania, Philadelphia, PA, USA 